\title{
Tempo de concentração para Bacias Rurais Monitoradas na Região do Planalto Basáltico no Sul do Brasil
}

\section{RESUMO}

O presente estudo teve por objetivo desenvolver uma equação para estimar o tempo de concentração (tc) de bacias hidrográficas rurais no sul do Brasil, utilizando o método hidrológico, que considera o tc como o tempo decorrido entre o fim da precipitaçáo efetiva e o fim do escoamento superficial. Na série de dados utilizada foi possível separar 30 eventos de chuva e vazão para cada bacia analisada, para estimativa do tc. Os resultados da equação obtida para as bacias foram comparados com os determinados usando 13 equaçóes empíricas desenvolvidas para bacias hidrográficas rurais. $\mathrm{O}$ tc médio determinado pelo método hidrológico usando 20 eventos de chuva e vazão permitiu determinar uma equação de tc utilizando o comprimento do rio principal $(\mathrm{L})$, a área da bacia (A) e a declividade do rio (S), para as bacias dos rios Donato $\left(1,10 \mathrm{~km}^{2}\right)$, Turcato $\left(19,25 \mathrm{~km}^{2}\right)$ e Taboáo $(77,50$ $\mathrm{km}^{2}$ ). A verificação desta equaçáo foi realizada com os 10 eventos restantes para cada uma das bacias. $\mathrm{O}$ tc médio dos 20 eventos foi de 2,96, 9,53 e 19,09 horas, respectivamente para as bacias dos rios Donato, Turcato e Taboão. Para a bacia do Donato, o tc estimado pela equação de Simas-Hawkins foi o mais representativo, sendo que subestimou em $25,57 \%$ quando comparado com o obtido com o método hidrológico. A melhor equação para estimar o tc da bacia do Turcato foi a de SCS Lag, porém subestimou em 16,06\%, enquanto a de Pasini foi a melhor para a bacia do Taboão e subestimou em $5,60 \%$. Essas equações apresentaram os melhores resultados em relação a equaçáo proposta no presente estudo. Entretanto, ressalta-se a importância em utilizar métodos que utilizam dados monitorados nas bacias analisadas.

Palavras-Chave: Tempo de concentração; Método hidrológico; Bacias hidrográficas rurais

\section{ABSTRACT}

The present study aimed to develop an equation to estimate the time of concentration for rural watersheds in southern Brazil, using the hydrological method, which considers the time of concentration as the time elapsed between the end of effective precipitation and the end of the runoff. The data series used were separated 30 rain and flow events to estimate time of concentration (tc). The results of the equation obtained for the watersheds were compared with the determined using 13 empirical equations developed for rural watersheds. The average of the tc determined by the hydrological method using 20 rain and flow events allowed to determine an equation of tc using the main river length (L), the basin area (A) and the slope of the river $(S)$, to the basins of the rivers Donato $\left(1,10 \mathrm{~km}^{2}\right)$, Turcato $\left(19,25 \mathrm{~km}^{2}\right)$ and Taboão $\left(77,50 \mathrm{~km}^{2}\right)$. The verification of this equation was performed with the 10 remaining events for each of the watersheds. The average tc to 20 events was $2,96,9,53$ and 19,09 hours respectively for the watersheds of the rivers Donato, Turcato and Taboao. The tc estimated by the equation of Simas-Hawkins was $25,57 \%$ less than the tc obtained with the hydrological method, being the most representative for the watershed of Donato. Already the SCS Lag equation underestimated $16,06 \%$ the tc to Turcato watershed, while that Pasini underestimated in $5,60 \%$ for the Taboão watershed. These equations presented the best results. However, it should be noted the importance to use methods that use metered data of the watersheds.

Keywords: Water supply; Sanitation; Water sustentability

de vazóes máximas, tanto para pequenas, como para grandes bacias hidrográficas. No entanto, sua determinação, muitas vezes, está fundamentada em métodos de natureza empírica, fato esse que permitiu o desenvolvimento de diversas equaçóes que consi- drográfica é um parâmetro fundamental para análises hidrológicas, como por exemplo, na determinação

\section{INTRODUÇÃO}

O tempo de concentração (tc) de uma bacia hi- 
deram as características geométricas da bacia hidrográfica, com a finalidade de estimar esse parâmetro.

Segundo Mota e Kobyiama (2015) o surgimento do termo tempo de concentração é atribuído ao engenheiro civil Thomas James Mulvany em 1851, que o conceituou como o tempo necessário para que uma partícula de água que atinge o ponto mais distante da bacia hidrográfica chegue ao exutório desta, indicando assim, que toda bacia hidrográfica contribui para a vazão que chega ao exutório. Essa mesma definição é apresentada por Kirpich (1940) e Ramser (1927), entre outros trabalhos. O entendimento do tempo de concentração assume um papel muito importante, uma vez que permite compreender o comportamento do escoamento superficial na bacia hidrográfica, o qual está associado a diversos fenômenos como: erosão do solo, transporte de sedimentos, enxurradas, ocorrência de enchentes, entre outras. Tais fenômenos podem trazer prejuízos socioeconômicos e ambientais no meio em que ocorrem.

Devido à importância do tempo de concentração para a Hidrologia, foram realizados vários estudos em diferentes bacias hidrográficas, com o objetivo de aprimorar o conhecimento desse parâmetro, dos quais foram originadas e analisadas, diversas equaçóes empíricas, como as de Kirpich (RAMSER, 1927; KIRPICH,1940; SILVEIRA, 2005; MOTA, 2012; MOTA \& KOBIYAMA 2015), Simas \& Hawkins (1996), Watt e Chow (WATT \& CHOW, 1985; MOPU, 1987; SILVEIRA, 2005), Carter (McCUEN et al. 1984), Dooge (USDA, 1973; PORTO, 1995), método cinemático (PORTO, 1995; SILVEIRA, 2005; COLLISCHONN \& DORNELLES, 2013), corpo de engenheiros do exército dos EUA (MOPU, 1987; SILVEIRA, 2005), entre outras.

Observa-se que existe um grande número de equaçóes para descrever o tempo de concentração de uma bacia hidrográfica, que podem resultar em valores muito distintos, em função das variáveis e parâmetros utilizados nas diferentes equaçóes.

Desta forma, é importante avaliar a aplicação destas equaçóes, comumente utilizadas no Brasil para a obtenção do tempo de concentração, uma vez que, esse é um parâmetro muito utilizado em diversos modelos que transformam chuva em vazão, em projetos de obras estruturais, as quais tem um custo associado se forem sobrestimadas ou subestimadas. Como a ba- cia hidrográfica é um sistema complexo e dinâmico, o tc depende de diversos fatores. As equaçóes empíricas fazem uso de coeficientes determinados para bacias hidrográficas específicas, que, muitas vezes, não são representativos para outras. Portanto, pode-se inferir que, nem sempre o tempo de concentração calculado por estas equaçóes, reflete a realidade.

\section{OBJETIVO}

O presente estudo teve por objetivo desenvolver uma equação para estimar o tempo de concentraçáo de bacias hidrográficas rurais, localizadas no noroeste do estado do Rio Grande do Sul, utilizando o método hidrológico e considerando como tempo de concentração o tempo decorrido entre o final da precipitação efetiva e o final do escoamento superficial. Em acréscimo, foram comparados os resultados obtidos com os estimados por 13 equaçóes desenvolvidas por outros autores, para bacias rurais.

\section{CONSIDERAÇÓES SOBRE O TEMPO DE CONCENTRAÇÁO}

O tempo de concentração é entendido como o tempo necessário para que toda área de uma bacia hidrográfica contribua para o escoamento superficial na saída de uma secção (SILVEIRA, 2005; KIRPICH, 1940; RAMSER, 1927). Ainda, Gergov (1971) apresenta em seu estudo o termo tempo de viagem, o qual segundo o referido autor representa o intervalo de tempo requerido para um dado volume de água fluir entre dois pontos ao longo da rede de drenagem, assumindo assim a característica do tempo de concentração, quando consideramos o tempo para que um dado volume de água no ponto mais distante da bacia hidrográfica chegue ao exutório desta.

Segundo McCuen et al. (1984), existem duas definiçóes comumente aceitas a respeito do tempo de concentração, sendo: a primeira, que o tc é definido como o tempo requerido para a partícula escoar hidraulicamente do ponto mais distante da bacia hidrográfica até o exutório desta; e a segunda, baseia-se na relação entre o hietograma da chuva efetiva e o ponto de inflexão, na curva de recessão do hidrograma, ao considerar que o tempo de concentração é dado pelo tempo entre o centro de massa do excesso de chuva 
e a inflexão dada na recessão do hidrograma. Tucci et al. (2009) bem como Kobiyama et al. (2006), ao abordarem a segunda definição descrita por McCuen et al. (1984), descrevem que o cálculo do tempo de concentração de uma bacia hidrográfica pode ser contemplado de forma gráfica, desde que haja registro do hietograma de chuva efetiva e do hidrograma. Assim, o tempo de concentração pode ser calculado como o tempo decorrido entre o término da chuva efetiva que gerou o escoamento e o resultado do escoamento superficial obtido do hidrograma, de modo a simplificar o processo. Apesar de McCuen et al. (1984) considerar que esse tempo seja contado a partir do centro de massa da precipitação, os mesmos autores propóem como alternativa, estimar o tc pela diferença de tempo entre o fim da precipitaçáo efetiva e o ponto de inflexão na recessão do hidrograma.

Em clima temperado, como no sul do Brasil, há grande variação de temperatura entre o inverno e o verão, chegando a temperaturas máximas superiores a $40^{\circ} \mathrm{C}$ no verão e mínimas inferiores a zero graus no inverno. Essa enorme diferença, influencia a evapotranspiração potencial das culturas, como da soja por exemplo, que pode variar de $0,7 \mathrm{~mm} \cdot \mathrm{dia}^{-1}$ no inverno a 7,0 mm.dia ${ }^{-1}$ no verão, influenciando na grande variação no teor de água no solo, e consequentemente na geração de escoamento na bacia e no seu respectivo tempo de concentração.

Portanto, o tempo de concentração, em bacias hidrográficas rurais e principalmente em climas temperados é dependente dos eventos e das condiçôes físicas (uso do solo) da bacia no momento da ocorrência do evento, além dos diversos fatores com importância comprovada, a exemplo da forma da bacia, comprimento de rio e declividade do rio. Outro fator importante de ser avaliado é o manejo do solo. Se o solo foi recentemente arado, por exemplo, haverá mais infiltração e menos escoamento superficial, logo, o tempo de concentração será maior. Já se o solo estiver compactado, haverá mais escoamento superficial e, consequentemente, menor será o tempo de concentração. Isso foi observado por Castro et al. (1999) ao realizar um experimento com simulaçáo de chuvas, em uma bacia hidrográfica, localizada no noroeste do estado do Rio Grande do Sul, encontrando valores de coeficiente de escoamento entre 25 e $88 \%$, sendo o menor valor para o solo recentemente arado e, o maior valor quando o solo estava compactado e havia se passado vários meses após o preparo do solo.

Considerando esses aspectos, salienta-se, que foram descritas na literatura um grande número de equaçóes com o objetivo de estimar, da melhor forma possível, o tempo de concentração de uma bacia hidrográfica. É válido ressaltar que o tempo de concentração depende de vários fatores físicos da bacia hidrográfica, bem como da chuva que gerou o escoamento, os quais podem afetar o seu percurso espacial e temporal, quando sofrem modificaçóes ao longo do tempo (TUCCI et al., 2009; SILVEIRA, 2005; McCUEN et al., 1984; SIMAS e HAWKINS, 1996; KIRPICH, 1940; RAMSER, 1927). Entre esses fatores citam-se: as condiçóes de cobertura do solo; impermeabilização; condições da hidráulica dos canais (declividade, revestimento); os compartimentos geológicos do solo; a variabilidade das intensidades e duraçôes das chuvas; forma da bacia hidrográfica; distância medida no fundo do talvegue (sinuoso), entre o ponto mais afastado e o exutório da bacia hidrográfica; condições do solo no início da chuva (umidade, porosidade, densidade do solo nas diferentes profundidades, selamento superficial); e caminhos preferenciais da água. Nesse sentido, a bacia hidrográfica não possui um tempo de concentração válido para todos os eventos.

Diversas bacias hidrográficas no Brasil, ainda não possuem monitoramento e, consequentemente, não possuem dados suficientes para permitir o cálculo do seu tempo de concentração, pelo método hidrológico, ou seja, pela análise do hietograma e do hidrograma. Existem diversas equaçóes empíricas desenvolvidas com base nos aspectos físicos da área de estudo obtidos de mapas topográficos, tais como: a declividade do terreno, o comprimento do rio principal, a área das bacias hidrográficas, entre outros. Empregando-se essas equaçóes é possível estimar o tempo de concentração da bacia hidrográfica, sem a necessidade de monitoramento (chuva e vazáo) da mesma. Resta saber qual das equaçóes é a mais eficiente para cada situação.

Uma das equaçôes frequentemente encontradas na literatura para o cálculo do tempo de concentração é a de Kirpich (1940), a qual foi desenvolvida com base em pequenas bacias hidrográficas agrícolas no estado de Tennessee (EUA). Entretanto, conforme Mota e 
Kobiyama (2015) acertadamente apontaram em seus estudos, a fórmula de Kirpich náo foi publicada por ele em 1940, e náo se originou do banco de dados que ele utilizou, destacando assim, a importância de avaliar os artigos originais para confirmar as informaçôes descritas em trabalhos posteriores. Essa equação denominada de Kirpich, provavelmente está associada aos estudos de Rowe (1957, apud CHOW, 1962), o qual obteve um equacionamento para determinação do tempo de concentração baseado em diversos dados, os quais se aproximam dos estudos de Ramser (1927) e Kirpich (1940). Considerando a equação de Kirpich como vem sendo usada, Silveira (2005) explica que ela pode ser aplicada para bacias hidrográficas de médio porte, inferiores a $12.000 \mathrm{~km}^{2}$, de maneira a proporcionar boas estimativas, mas não para inferiores a 26,2 $\mathrm{km}^{2}$. Esse fator apresentado por Silveira (2005) contrasta com os dados apresentados por Ramser (1927), Kirpich (1940) e as informações de Mota e Kobiyama (2015), que aponta que a equaçáo foi desenvolvida para bacias hidrográficas com áreas inferiores a 0,45 $\mathrm{km}^{2}$, sendo que, considerando os dados encontrados, Kirpick (1940) explica que a aplicação do equacionamento seria recomendada para áreas entre 0,004 e $0,81 \mathrm{~km}^{2}$. Considerando todos os pontos salientados até aqui, é válido destacar as variáveis que compóem a equação de Kirpich como a conhecemos, são elas: o comprimento (L) e a declividade do rio principal (S).

Já a equação SCS (US Soil Conservation Service) é representativa para pequenas bacias hidrográficas rurais, considerando que foi concebida com dados de bacias hidrográficas rurais americanas de no máximo $8 \mathrm{~km}^{2}$. Para utilizar esta equação necessita-se do comprimento do rio principal (L), sua declividade (S) e o Método do Número da Curva (CN), o qual é determinado em função do uso, ocupação e manejo do solo, além do grupo hidrológico do solo, da condição hidrológica e da umidade antecedente do solo (SILVEIRA, 2005; MCCUEN, 1998).

Simas e Hawkins (1996) basearam-se em uma equação que tenta representar o tempo decorrido entre o centroide da precipitaçáo e o centroide do escoamento superficial, conhecido como tempo de retardo. No entanto, Silveira (2005) apresenta uma formulação da mesma equação, a qual é contemplada na obtenção do tempo de concentração, sendo função de 3 variáveis explicativas: a largura média da bacia (A/L), a declividade do talvegue principal (S) e o ar- mazenamento (Sscs). Sendo esta última dependente do parâmetro CN. Para efeito do presente estudo, a formulação é aquela indicada em Silveira (2005), a qual apresenta uma pequena alteração nos termos da equação original para permitir o cálculo do tc de forma mais simples, e, conforme o referido autor explica, seria aplicável em bacias inferiores a $15 \mathrm{~km}^{2}$.

$\mathrm{Na}$ equação de Ven Te Chow, utiliza-se o comprimento do rio principal (L) e a declividade do mesmo (S) para determinar o tempo de concentração. Esta equaçáo se baseia em dados coletados de 20 bacias hidrográficas rurais e é recomendada para áreas variando entre 1,1 e $19 \mathrm{~km}^{2}$. Silveira (2005) apresenta uma formulação dessa equação considerando os estudos do MOPU (1987) e DAEE (1978, apud SILVEIRA, 2005). O equacionamento utilizado para a estimativa do tc por este método é o proposto por Silveira (2005).

A equação de tempo de concentração de Dooge, conforme Silveira (2005) explica, foi apresentada no Brasil por Porto (1995). Os estudos de USDA (1973) apresentam a referida equação com uma pequena diferença daquela apresentada por Silveira (2005). A equação relaciona tempo de concentração com a área da bacia hidrográfica $(\mathrm{A})$ e a declividade do rio principal (S). Conforme os autores explicam, o desenvolvimento dessa equação perpassa pelos dados de 10 bacias hidrográficas na Irlanda com áreas variando entre 145,04 e $947,94 \mathrm{~km}^{2}$.

A equação de tempo de concentração de Johnstone, conforme USDA (1973) foi obtida utilizando o método de Clark para 19 bacias hidrográficas, sendo recomendada para áreas entre 64,75 e $4.206,14 \mathrm{~km}^{2}$. Essa formulação foi desenvolvida com dados das bacias hidrográficas de Scotie e Sandusky e utiliza as mesmas informaçóes de Ven te Chow, sendo L o comprimento do rio principal e $S$ a declividade do mesmo.

A equação Corps Engineers (Equação do Corpo de Engenheiros do Exército dos EUA) foi baseada em 25 bacias hidrográficas rurais de até $12.000 \mathrm{~km}^{2}$ situadas nos EUA, em que o comprimento do rio principal era menor que $257 \mathrm{~km}$ (Silveira, 2005). As informaçóes utilizadas foram L para o comprimento do curso d'água principal e $S$ para sua declividade.

As equações Giandotti, Pasini e Ventura são indicadas para bacias rurais médias e pequenas, conforme descrito por Silveira (2005), sendo desenvolvidas com dados de bacias hidrográficas localizadas na Itália. $\mathrm{O}$ equacionamento proposto por Giandotti e Pasini uti- 
liza a área da bacia (A), comprimento do rio principal (L) e sua declividade (S), enquanto Ventura utiliza os dados da área (A) e da declividade do rio principal (S). A equação de Picking, também se encaixa na mesma definição aplicada para as 3 anteriores, já que se tem pouca informação sobre sua formulação. As informaçôes necessárias para utilização da equação são o comprimento do rio principal (L) e a declividade do mesmo $(S)$.

As equaçóes DNOS (Departamento Nacional de Obras de Saneamento) e George Ribeiro, foram desenvolvidas no Brasil, sendo de autoria do próprio Ribeiro. A equação do DNOS apresenta-se como uma adaptação da fórmula Bransby-Williams, onde foi introduzido o coeficiente $\mathrm{k}$, que representa as características do terreno da bacia hidrográfica com valores que vão de 2 a 5,5 , sendo 2 para solo com elevada absorção e 5,5 para baixa absorção, além de dados da área da bacia hidrográfica (A), comprimento do rio principal (L), declividade (S) (SILVEIRA, 2005). Já na equação que leva o nome do próprio Ribeiro, utilizam-se os dados de comprimento do rio principal (L), declividade (S) do rio e a variável p, que é um coeficiente que representa a fração de área com mata, variando entre 0 e 1 (SILVEIRA, 2005). Esta equação foi uma tentativa de buscar uma base física nas relaçóes entre L, S, a velocidade do escoamento, e a rugosidade da superfície.

Na Tabela 1 são apresentadas as 13 equaçóes utilizadas para o cálculo do tempo de concentração em bacias rurais, conforme Silveira (2005). O mesmo autor aponta que as equaçóes foram desenvolvidas utilizando 6 a 148 bacias. No entanto, para as equaçôes do SCS Lag, Giandotti, Pasini, Ventura e Picking não foram encontradas informaçóes acerca do número de bacias utilizadas para propor os equacionamentos. $\mathrm{O}$ que indica que o número de bacias para propor um equacionamento é bastante variável, bem como do número de eventos a serem utilizados. A equação de Simas-Hawkins (1996), por exemplo, que utilizou 168 bacias e aproximadamente 50.000 eventos é recomendada para bacias com áreas inferiores a 15 $\mathrm{km}^{2}$, enquanto a de Kirpich (1940) considerando dados de 6 bacias e 9 a 11 eventos (RAMSER, 1927) é recomendada para bacias inferiores a $12.000 \mathrm{~km}^{2}$ (SILVEIRA, 2005).

Tabela 1- Equaçốes para o cálculo do tempo de concentração (tc)

\begin{tabular}{|c|c|c|}
\hline Nome & Equação & Área aplicável $\left(\mathrm{km}^{2}\right)$ \\
\hline Kirpich & $\mathrm{tc}=0,0663 \mathrm{~L}^{0,77} \mathrm{~S}^{-0,385}$ & $<12.000$ \\
\hline SCS Lag & $\mathrm{tc}=0,057(1000 / \mathrm{CN}-9)^{0,7} \mathrm{~L}^{0,8} \mathrm{~S}^{-0,5}$ & $<8,1$ \\
\hline Simas- Hawkins & $\mathrm{tc}=0,322 \mathrm{~A}^{0,594} \mathrm{~L}^{-0,594} \mathrm{~S}^{-0,150} \mathrm{~S}_{\mathrm{scs}}^{0,313}$ & $<15$ \\
\hline Ven te Chow & $\mathrm{tc}=0,160 \mathrm{~L}^{0,64} \mathrm{~S}^{-0,32}$ & $<12.000$ \\
\hline Dooge & $\mathrm{tc}=0,365 \mathrm{~A}^{0,41} \mathrm{~S}^{-0,17}$ & $145,04-947,94$ \\
\hline Johnstone & $\mathrm{tc}=0,462 \mathrm{~L}^{0,5} \mathrm{~S}^{-0,25}$ & $64,75-4206,14$ \\
\hline Corps Engineers & $\mathrm{tc}=0,191 \mathrm{~L}^{0,76} \mathrm{~S}^{-0,19}$ & $<12.000$ \\
\hline Giandotti & $\mathrm{tc}=0,0559\left(4,0 \mathrm{~A}^{0,5}+1,5 \mathrm{~L}\right) \mathrm{L}^{-0,5} \mathrm{~S}^{-0,5}$ & - \\
\hline Pasini & $\mathrm{tc}=0,107 \mathrm{~A}^{0,333} \mathrm{~L}^{0,333} \mathrm{~S}^{-0,5}$ & - \\
\hline Ventura & $\mathrm{tc}=0,127 \mathrm{~A}^{0,5} \mathrm{~S}^{-0,5}$ & - \\
\hline Picking & $\mathrm{tc}=0,0883 \mathrm{~L}^{0,667} \mathrm{~S}^{-0,333}$ & - \\
\hline DNOS & $\mathrm{tc}=0,419 \mathrm{k}^{-1} \mathrm{~A}^{0,3} \mathrm{~L}^{0,2} \mathrm{~S}^{-0,4}$ & $<0,45$ \\
\hline George Ribeiro & $\mathrm{tc}=0,222(1,05-0,2 p)^{-1} \mathrm{LS}^{-0,04}$ & $<19.000$ \\
\hline
\end{tabular}

Fonte: Adaptado de Silveira (2005)

tc (horas), A (km²), L (km), S (m/m), $S_{\text {scs }}(\mathrm{mm}), \mathrm{CN}, \mathrm{p}(0,5)$ e k (3) (adimensionais). 


\section{MATERIAL E MÉTODOS}

\section{Área de estudo}

O estudo foi realizado em três sub-bacias embutidas na bacia hidrográfica do rio Potiribu, localizadas no noroeste do Rio Grande do Sul, no município de Pejuçara: (a) bacia hidrográfica do rio Donato $\left(1,1 \mathrm{~km}^{2}\right)$, (b) bacia hidrográfica do rio Turcato $\left(19,25 \mathrm{~km}^{2}\right)$ e (c) bacia hidrográfica do Taboão $\left(77,5 \mathrm{~km}^{2}\right)$, (Figura 1). Essas bacias hidrográficas são monitoradas pelo Instituto de Pesquisas Hidráulicas (IPH) da UFRGS, desde 1989, constituindo atualmente 28 anos de dados hidrológicos, com o objetivo de melhor compreender e representar o comportamento dos processos hidrossedimentológicos (CASTRO et al., 2010). A região em estudo apresenta formação geológica, solos, relevo e clima muito característicos da parte central do derrame basáltico do Sul do Brasil (BORDAS e BORGES, 1990).

\section{Características físicas das bacias hidrográficas e dados utilizados}

De acordo com Carvalho et al. (1990), que realizaram um levantamento de solos na bacia de estudo, na escala 1:25.000, os solos predominantes são Latossolos vermelhos (71,49\%), e Nitossolos (23,45\%). Também estão presentes em menores proporções os Neossolos (2,76\%) e Gleissolos Háplico (2,29\%). Os Latossolos se caracterizam por serem profundos (com mais de $8 \mathrm{~m}$ de profundidade), de textura argilosa (em geral com mais de 55\% de argila), porém bem drenados, devido à presença de agregados, que confere ao solo uma boa infiltração. Já os Nitossolos são constituídos por material mineral, apresentam-se com textura argilosa ou muito argilosa e com o horizonte B nítico. Os Neossolos, por sua vez, apresentam-se constituídos por material mineral ou por material orgânico pouco espesso, ou seja, com pouco desenvolvimento pedogenético, sendo considerado solo novo.

Figura 1 - Localização das bacias hidrográficas, estações fluviométricas e pluviógrafos utilizados

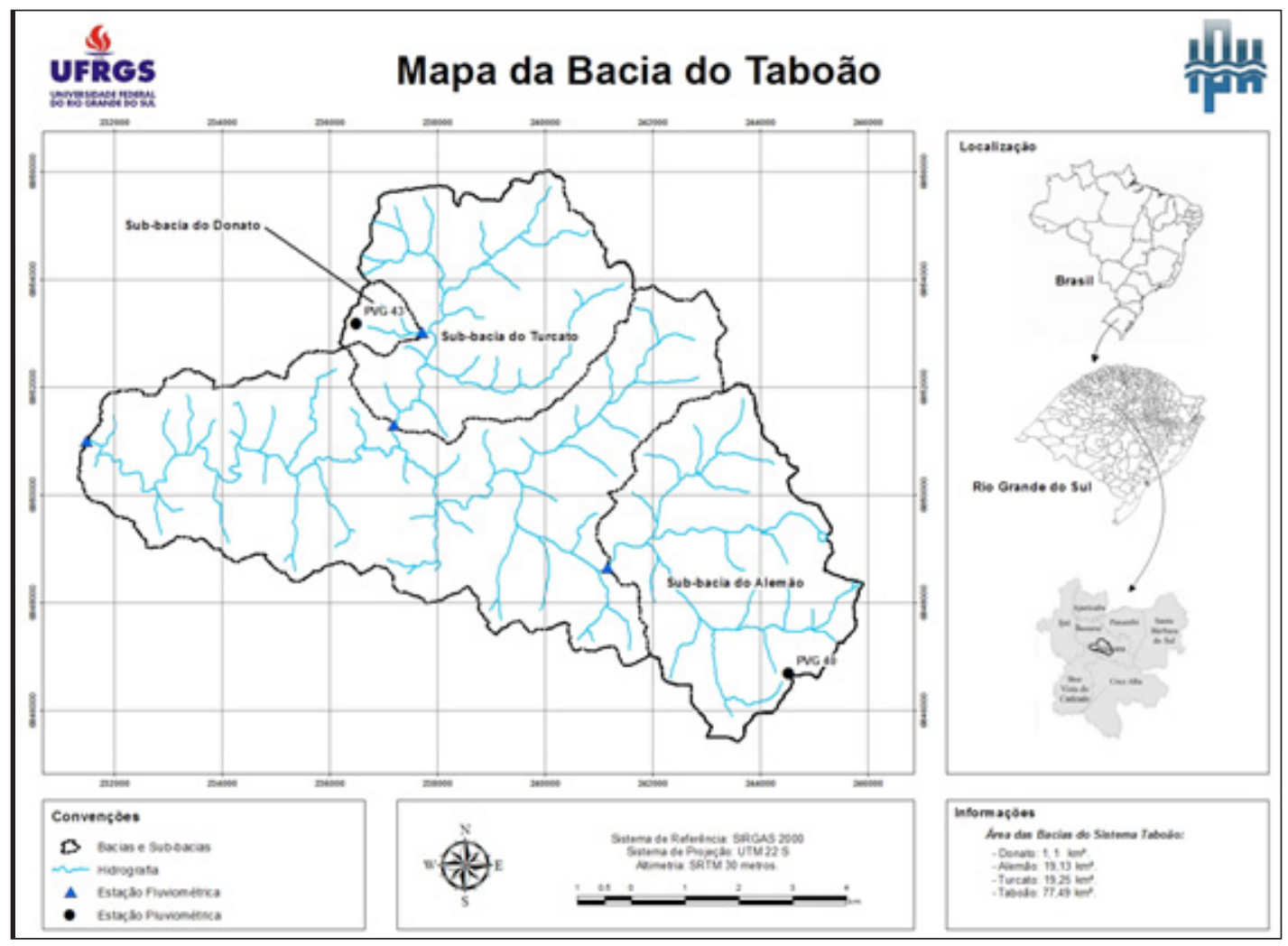


Por fim, os Gleissolos são constituídos por material mineral e caracterizam-se por apresentar horizonte de cores cinza associadas ao hidromorfismo (EMBRAPA, 2006; JACOMINE, 2009). O uso do solo é apresentado na Figura 2, a qual informa que na bacia do rio Taboão $89 \%$ do uso do solo é destinado para a agricultura, $7,1 \%$ correspondem as matas, a área urbana abrange $2,3 \%$, as estradas ocupam $1,4 \%$, zonas de campo correspondem a $0,15 \%$ e a água está presente em $0,05 \%$ da área total da bacia. Observa-se assim a predominância do uso agrícola na referida bacia.

As altitudes das bacias hidrográficas desse estudo estão entre 340 e 490 m (Figura 3), com declividades variando de 3 a $22 \%$ (Tabela 2 ).

Figura 2 - Uso do solo na bacia do rio Taboão

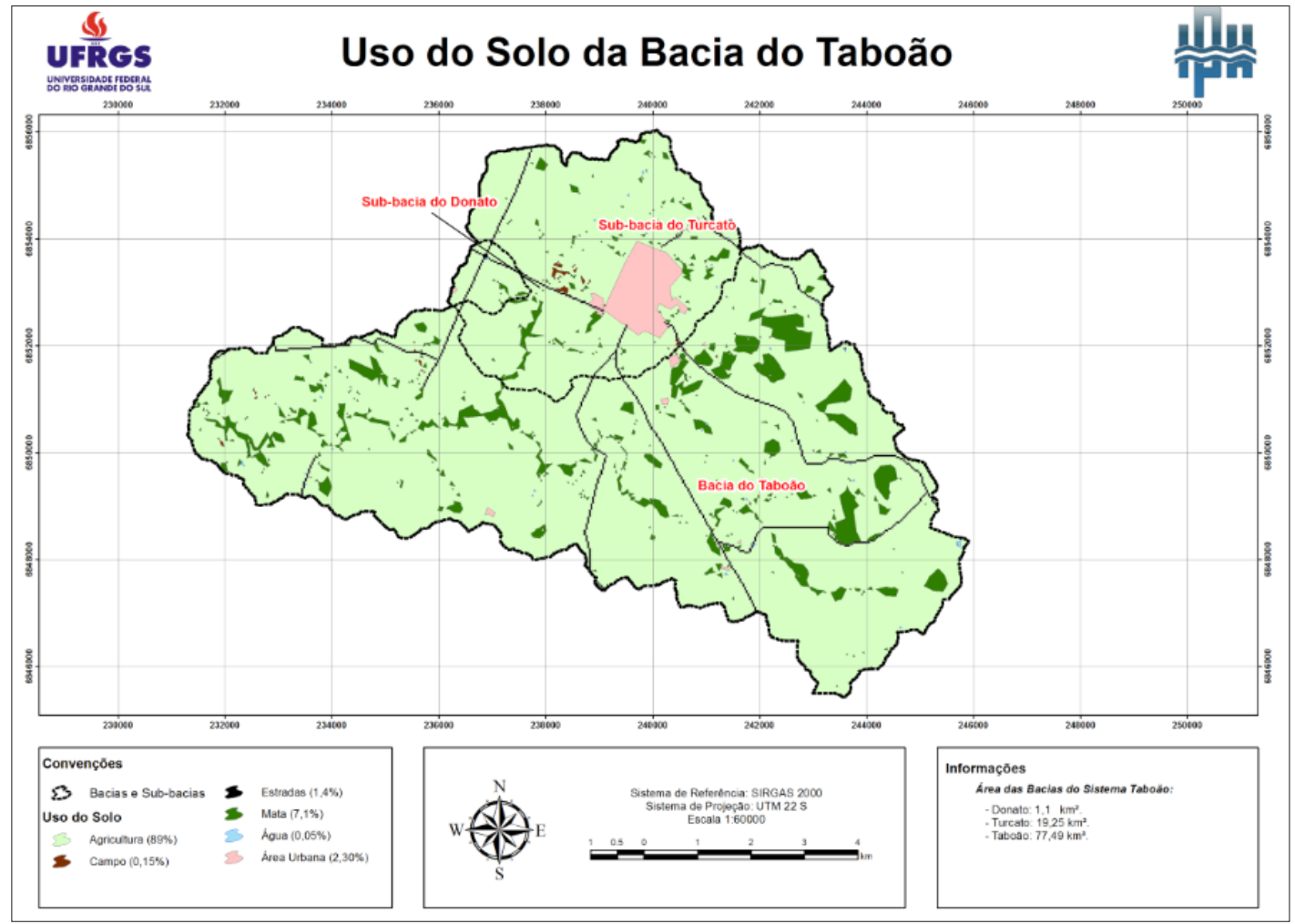

Tabela 2 - Declividades por sub-bacias

\begin{tabular}{c|c|c|c}
\hline \multirow{2}{*}{ Classes de declive (graus) } & \multicolumn{3}{|c}{ Porcentagem das classes de declive (\%) } \\
\cline { 2 - 2 } & Donato & Turcato & Taboão \\
\hline $0^{\circ}$ a $2^{\circ}$ & 15,44 & 12,54 & 16,14 \\
\hline $2^{\circ}$ a $4^{\circ}$ & 36,33 & 36,11 & 37,58 \\
\hline $4^{\circ}$ a $6^{\circ}$ & 32,49 & 34,78 & 30,41 \\
\hline $6^{\circ}$ a $8^{\circ}$ & 12,22 & 13,07 & 14,27 \\
\hline $8^{\circ}$ a $10^{\circ}$ & 2,65 & 2,76 & 1,60 \\
\hline$>10^{\circ}$ & 0,86 & 0,74 & 0,00 \\
\hline
\end{tabular}

Fonte: CGIAR-CSI (2017) 
Figura 3 - Curva hipsométrica para a bacia hidrográfica do rio Taboão

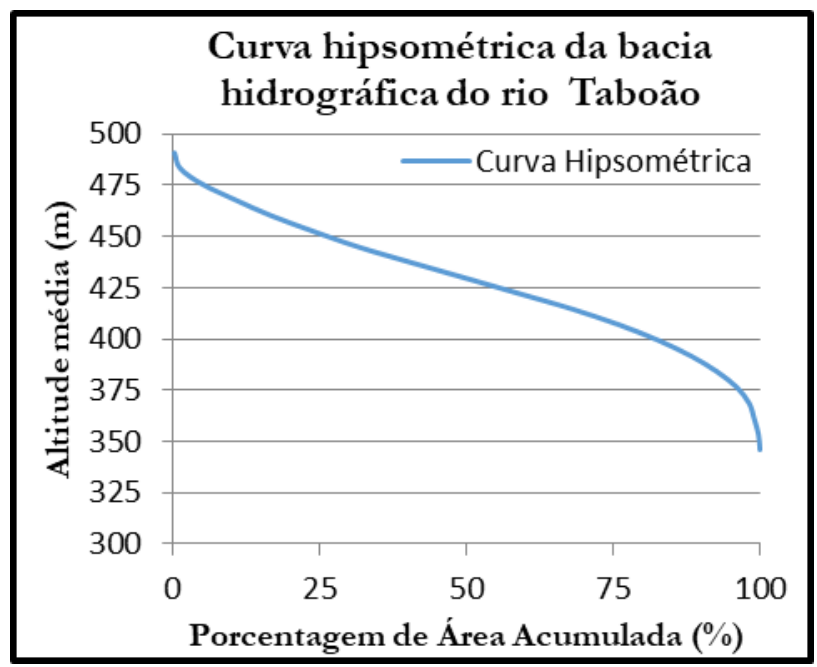

Essa região é caracterizada por ter intensa atividade agrícola, com dois ciclos de cultura por ano: soja e milho no verão (dezembro a março), e aveia e trigo no inverno (junho a setembro). Desde a década de 1990, vem sendo utilizado o método de plantio direto na região, que se caracteriza pelo não revolvimento do solo, sendo o plantio feito em sulcos abertos sobre os restos (palha) da cultura anterior. A vegetação nativa é característica da Mata Atlântica a qual atualmente se restringe a mata ciliar em torno dos rios.

Conforme a classificação de Koeppen, o clima da região é mesotérmico brando, do tipo temperado, super-úmido e sem estação seca (cfa) (NIMER, 1989). As temperaturas médias mensais situam-se entre $14^{\circ} \mathrm{C}$ (mês de julho) e $24^{\circ} \mathrm{C}$ (mês de janeiro). A média das temperaturas máximas é superior a $22^{\circ} \mathrm{C}$, e a média das mínimas oscila entre -3 e $18^{\circ} \mathrm{C}$ (IPAGRO, 1989).

Para determinar a média mensal de chuva da região foi utilizada a série histórica de 1958 a 2004 obtida da estação pluviométrica de Passo Faxinal (02853010), de responsabilidade da Agência Nacional das Águas (ANA)/Serviço Geológico do Brasil (CPRM), localizada no município de Ijuí-RS. A média mensal de chuva na regiáo varia entre $113,93 \mathrm{~mm}$, no mês de março (outono) e 179,17 mm em outubro (primavera), sendo que, a média mensal é de $140,8 \mathrm{~mm}$ e anual de $1.693 \mathrm{~mm}$. De acordo com Chevallier e Dhein (1993) a variabilidade média mensal é baixa, porém podem ocorrer eventos extremos de seca e de cheia, devido ao fenômeno El Niño, como em maio de 1992, onde ocorreu uma chuva de mais de $300 \mathrm{~mm}$ em 26 h. Entretanto, observou-se na série histórica que no ano de 2012 ocorreu uma grande seca, sendo que entre o mês de agosto de 2012 e dezembro de 2013 não ocorreu nenhuma chuva, indicando alta variabilidade de chuva interanual.

Para estimar o tc usando os parâmetros físicos das bacias, como comprimento do rio principal (L), área de drenagem (A) e declividade média $(\mathrm{S})$ foram utilizados: o modelo digital de elevação SRTM (Shuttle Radar Topographic Mission), com resoluçáo de pixel de 30 × 30 m disponível no banco de dados do CGIAR-CSI pelo endereço: http://srtm.csi.cgiar. org/ (CGIAR-CSI, 2017). Esses parâmetros foram determinados com utilização do programa ArcGIS versão 10.3. As declividades foram determinadas pela diferença entre as cotas de montante e do exutório do rio principal para bacia hidrográfica, dividida pelo comprimento do rio principal. A equaçáo do DNOS, além dos parâmetros físicos, utiliza o fator $\mathrm{K}$, que é determinado com base nas características do terreno da bacia. Conforme Silveira (2005), para bacias com terrenos cobertos de vegetação e com absorção de água apreciável o fator Ké 3,0. Esse valor foi adotado para calcular o tc de todas as bacias de estudo, uma vez que, melhor caracterizam essa regiáo. 
O período dos dados utilizados neste trabalho foi de outubro de 2008 a outubro de 2016, medidos em três estações fluviométricas, localizadas no exutório das bacias dos rios Donato, Turcato e Taboão. As estações possuem réguas linimétricas e linígrafos com registro do nível do rio a cada 10 minutos. Devido às campanhas intensivas de coleta de dados e medição de vazão, realizadas ao longo dos 28 anos de monitoramento, todas as estaçôes possuem curva-chave. $\mathrm{Na}$ bacia do Donato, a menor delas, foi instalado um vertedor de concreto, sendo, portanto, a mesma equação da curva-chave válida para todo o período de estudo. Mesmo com a equação do vertedor, para transformar nível em vazão, foram realizadas 57 medições de vazão na seção, para aferição da curva-chave, a qual se manteve válida durante todos esses anos. Para a bacia do rio Turcato, a seção transversal do rio foi modificada algumas vezes, devido a eventos extremos de cheia. No período do estudo, entretanto, a seção se manteve a mesma, e foi utilizada a mesma curva-chave. Para esta curva, foram realizadas 69 mediçôes de vazão, sendo que estes pontos coincidiram com a antiga curva chave (de 1998 a 2003 com 53 mediçóes), válida até $30 / 06 / 2003$, portanto esta curva antiga foi utilizada para o período deste estudo $\left(r^{2}=0,987\right)$. Na bacia do Taboão, a seção transversal de medição, é bem estável e se manteve a mesma desde o início do monitoramento nesta bacia, que foi em novembro de 2001, portanto foi utilizada somente uma curva-chave, com 176 mediçóes realizadas entre 2001 e $2016\left(r^{2}=0,987\right)$. Através destas curvas-chaves, os registros dos níveis das três bacias foram transformados em vazão, a cada 10 minutos, e foram utilizados para a confecção dos hidrogramas e cálculo do tempo de concentração dos eventos.

Para os dados de chuva, foi utilizado o pluviógrafo 43, localizado a noroeste da bacia, dentro da sub bacia do Donato. Em casos de lacuna neste posto, foram utilizados os dados do pluviógrafo 40, localizado a sudeste da bacia. Pode-se assumir, que a chuva dos pluviógrafos 40 e 43 são representativas de toda a bacia $\left(77,5 \mathrm{~km}^{2}\right)$.

\section{Estimativa do Tempo de concentração (tc)}

O tempo de concentração das bacias dos rios Donato, Turcato e Taboão foi estimado por: (a) método hidrológico, utilizando dados de chuva e vazão medidos e posteriormente utilizados para a elaboração da equação ajustada para esta pesquisa; (b) equaçóes empíricas de vários autores (ver Tabela 1) indicadas para utilização em bacias hidrográficas rurais.

\section{a) Tempo de concentração (tc) calculado pelo método hidrológico}

Foram selecionados 30 eventos de cheia maiores, ocorridos no período analisado, sem falhas. Dos 30 eventos, 20 foram utilizados para elaboração de uma equação de tc ajustada para as bacias de estudo e, 10 para validação desta equação.

As curvas-chave utilizadas remontam aos estudos de Castro et al. (2000), o qual descreve as características e o histórico de cada posto fluviométrico avaliado. Dos 30 eventos selecionados na bacia do rio Donato, 2 apresentaram a vazão de pico superior a vazão máxima medida de $2,51 \mathrm{~m}^{3} / \mathrm{s}$ utilizada para aferir a equaçáo do vertedor instalado nessa bacia, representando as$\operatorname{sim} 6,67 \%$ dos dados utilizados. Para a bacia do rio Turcato, 16 dos 30 eventos selecionados apresentaram a vazáo de pico superiores ao maior dado medido $\left(12,36 \mathrm{~m}^{3} / \mathrm{s}\right)$ para compor a curva-chave dessa bacia, correspondendo a 53,3\% dos dados. Já para a bacia do Taboáo, 13 dos 30 eventos apresentaram a vazáo de pico mais elevada que a vazão máxima medida de $19,37 \mathrm{~m}^{3} / \mathrm{s}$ para compor a curva-chave, representando dessa forma 43,33\% dos eventos analisados.

A obtençấo do tc pelo método hidrológico consistiu em 3 etapas distintas: (i) separaçáo dos eventos de chuva e vazão nos respectivos hietogramas e hidrogramas; (ii) determinação da precipitação efetiva; e (iii) cálculo do tc.

i) A separação dos eventos de chuva e vazão foi feita a partir de hietogramas e hidrogramas elaborados com os dados dos 30 maiores eventos registrados, com o software Hydracess, de domínio livre, o qual contém o banco de dados hidrossedimentológicos das bacias hidrográficas de estudo. No Hydracess foi possível visualizar simultaneamente os hietogramas e hidrogramas na mesma escala temporal, e assim, identificar visualmente o início e o fim dos eventos de precipitação. Nos eventos de vazão, foi identificado visualmente o início do escoamento (ponto A) e foi adotado o critério do logaritmo das vazóes de recessão, para identificar a mudança na inflexão da curva no fim do hidrograma e, consequentemente o fim do escoamento superficial (ponto C), conforme Figura 4. 
Figura 4 - Critério do logaritmo das vazóes na recessão do hidrograma para identificar o ponto $\mathrm{C}$ para o evento do dia 09/08/2011 na bacia do Taboão (o mesmo procedimento foi adotado para os outros 89 eventos)

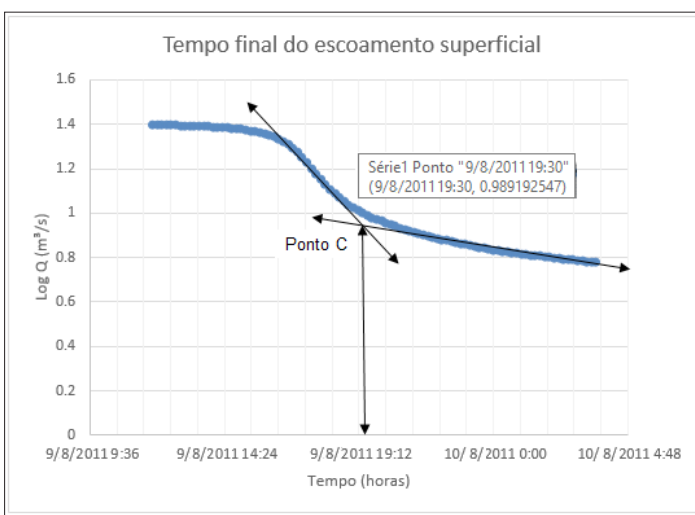

A chuva efetiva foi determinada para cada evento, dividindo-se o escoamento superficial (obtido anteriormente no Hydracess) pela área da bacia hidrográfica. Com esses resultados, foi obtido um índice de infiltração $(\varphi)$, usando método iterativo. Com objetivo de encontrar um valor de $\varphi$ mínimo, utilizou-se a ferramenta solver, disponível no software Excel versão 2013. Para efetuar essa operação a restrição utilizada no Solver foi a seguinte: a diferença entre a precipitação efetiva total e o somatório da diferença entre a precipitação e $\varphi$, para cada intervalo de tempo, tem que ser igual a zero. Com isso, obteve-se a parcela da chuva que infiltrou. A precipitação efetiva foi adotada como o somatório entre o primeiro dado de chuva até o dado de chuva que acarretasse no último valor superior a zero. Este último foi determinado pela diferença entre a precipitaçáo real e o $\varphi$, indicando, dessa forma, a parcela da chuva que gera escoamento superficial.

Por fim, o tc foi obtido pela diferença de tempo entre o fim do escoamento superficial e o fim da chuva efetiva conforme é apresentado na Figura 5.

Após a obtenção dos tcs pelo método hidrológico, dos 30 maiores eventos registrados simultaneamente para as três bacias, foram calculadas estatísticas descritivas do conjunto dos 20 primeiros eventos. Em um processo iterativo, os tcs médios dos 20 eventos das três bacias foram relacionados com a área (A), o comprimento do rio principal (L), e a declividade do rio principal $(S)$ de modo a satisfazer o seguinte equacionamento:
Figura 5 - Estimativa do tc pelo método hidrológico para o evento do dia 12/04/2014 para a bacia do rio Turcato

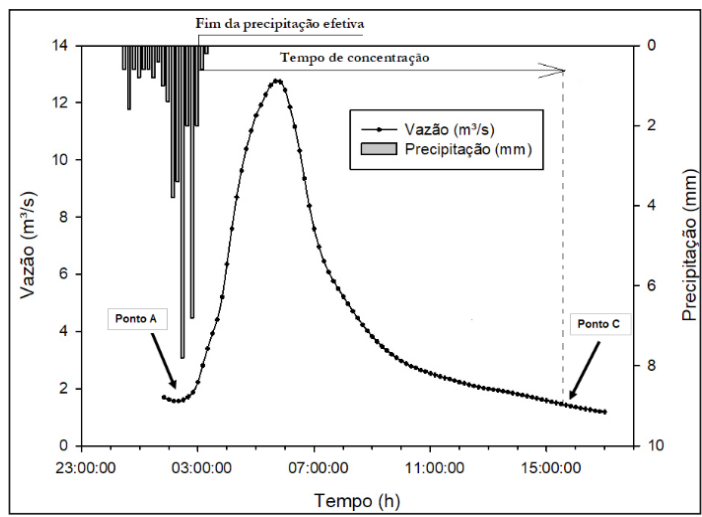

$$
t_{c}=\alpha \cdot L^{b} \cdot A^{c} \cdot S^{d}
$$

Por iteração foram obtidos a constante $\alpha$ e os expoentes b, c, d desses parâmetros descritos acima. Esse processo foi realizado até que o valor de tc se aproximasse do valor médio obtido pelo método hidrológico. Os outros 10 eventos foram utilizados para validar a equação proposta. Essa foi a única forma da função utilizada na regressão para a obtenção do tempo de concentração.

Para a análise dos resultados, foi utilizada estatística descritiva, comparando a média, mediana, valor máximo, valor mínimo e desvio padrão dos tempos de concentraçấo obtidos pelos diferentes métodos.

\section{b) Tempo de concentração (tc) calculado com equaçôes empíricas para bacias rurais}

O tc também foi calculado usando 13 equaçóes empíricas (Tabela 1), as quais são indicadas para bacias hidrográficas rurais, como é o caso das bacias de estudo.

\section{RESULTADOS E DISCUSSÃO}

A Tabela 3 apresenta os parâmetros utilizados neste estudo para calcular o tc pelas equaçóes da Tabela 1 . Salienta-se que os valores de $\mathrm{p}, \mathrm{CN}$, SCS e k foram os mesmos para todas as bacias analisadas, uma vez que pertencem à mesma região. 
Tabela 3 - Características físicas das bacias de estudo

\begin{tabular}{c|c|c|c}
\hline \multirow{2}{*}{ Parâmetros físicos } & \multicolumn{3}{|c}{ Bacias hidrográficas } \\
\cline { 2 - 4 } & Donato & Turcato & Taboão \\
\hline $\mathrm{L}(\mathrm{km})$ & 1,30 & 6,84 & 23,50 \\
\hline $\mathrm{S}(\mathrm{m} / \mathrm{m})$ & 0,0254 & 0,0114 & 0,0053 \\
\hline $\mathrm{A}\left(\mathrm{km}^{2}\right)$ & 1,10 & 19,25 & 77,50 \\
\hline $\mathrm{CN}$ & 70 & 70 & 70 \\
\hline $\mathrm{p}$ & 0,50 & 0,50 & 0,50 \\
\hline $\mathrm{S}_{\mathrm{SCS}}(\mathrm{mm})$ & 108,86 & 108,86 & 108,86 \\
\hline $\mathrm{k}$ & 3 & 3 & 3 \\
\hline Desnível $(\mathrm{m})$ & 33 & 78 & 124 \\
\hline
\end{tabular}

Verifica-se na Tabela 4 que o tc obtido pelo método hidrológico, considerando os 20 primeiros eventos de vazáo, teve o desvio padrão variando $47,21 \%$, $21,41 \%$ e $5,31 \%$ em relação à média para as bacias do Donato, Turcato e Taboão respectivamente. Já para os últimos 10 eventos elencados na Tabela 5, a variação do desvio padrão em relação à média foi de $13,82 \%, 33,52 \%$ e $25,14 \%$ para as bacias do Donato, Turcato e Taboão respectivamente. Destes foi excluído dos cálculos estatísticos o evento 1 ocorrido na bacia do rio Donato, por ser considerado atípico, conforme mostra a Figura 6. O tc médio para os primeiros 20 eventos das bacias hidrográficas do Donato, Turcato e Taboão são de 2,96, 9,53, e 19,09 horas respectivamente e, para os últimos 10 eventos são de 1,49; 7,58 e 18,06 horas. Esses valores estáo coerentes com as dimensôes (comprimento e área) das bacias, ou seja, quanto maior a área da bacia, e o comprimento do rio principal, maior foi o tc. Entretanto observa-se que a média dos eventos da Tabela 5 foi 49,78\%, 20,42\% e 5,37\% inferior que as médias da Tabela 4 para as bacias do Donato, Turcato e Taboão respectivamente.

Utilizando os dados médios de tc obtidos pelo método hidrológico (Tabela 4), dos 20 eventos medidos nas três bacias hidrográficas foi proposta a seguinte equação para estimar o tc:

$$
t_{c}=0,676 \cdot L^{0,079} \cdot A^{0,296} \cdot S^{-0,289}
$$

onde: $t_{c}$ é o tempo de concentração (h); $L$ o comprimento do rio até o exutório da bacia hidrográfica (m); $A$ corresponde à área da bacia hidrográfica $\left(\mathrm{km}^{2}\right)$; e $S$ a declividade do rio principal $(\mathrm{m} / \mathrm{m})$. Cabe ressal- tar que na bacia do rio Donato foram eliminados os pontos atípicos conforme mostra a Figura 6.

Aplicando-se a Equaçáo 15, obteve-se 2,95 horas para a bacia do Donato, 9,49 horas para a bacia do Turcato e 19 horas para a bacia do Taboão.

Para validar a Equação 15 os 10 eventos (21 a 30) apresentados na Tabela 5 foram utilizados. Assim, a média do tc para a bacia do rio Donato ficou em 1,49 horas (sem os pontos atípicos), sendo 49,62\% inferior ao resultado obtido com Equação 15. Para a bacia do rio Turcato a média foi de 7,58 horas $(20,12 \%$ inferior a Equação 15). Já para a bacia do rio Taboão a média foi de 18,06 horas (4,96\% inferior). Observa-se que a medida que a área da bacia hidrográfica aumenta a equação apresenta melhores resultados.

$\mathrm{Na}$ Tabela 6 são apresentados os tcs calculados usando as equaçóes da Tabela 1, onde verifica-se uma grande variação entre os resultados. É possível observar que para a bacia hidrográfica do rio Donato o tc variou de 0,33 a 2,20 horas. Já para a bacia do rio Turcato o tc variou de 1,41 a 7,97 horas. A maior discrepância foi observada para a bacia do rio Taboão, onde a diferença variou entre 4,16 a 31,46 horas.

Para uma mesma bacia hidrográfica, o tc (Tabela 6) variou 5,65 (Turcato) a 7,56 (Taboão) vezes, dependendo da equação utilizada, ao comparar os valores máximos e mínimos. Apesar desta diferença, verifica-se resultados semelhantes nas 3 bacias hidrográficas aos encontrados pelas equaçóes de Kirpich, George Ribeiro e Picking. Essas equaçóes utilizam os mesmos parâmetros físicos para calcular o tc, porém coeficientes empíricos diferentes, que podem ter 
Tabela 4 - Tempo de concentração obtido pelo método hidrológico para calibrar a equação "Projeto Potiribu"

\begin{tabular}{|c|c|c|c|c|c|c|c|}
\hline \multirow[t]{2}{*}{ Item } & \multirow[t]{2}{*}{ Evento } & \multicolumn{2}{|l|}{ Donato } & \multicolumn{2}{|l|}{ Turcato } & \multicolumn{2}{|l|}{ Taboão } \\
\hline & & $\begin{array}{l}\text { Data - Hora } \\
\text { (Fim da cheia) }\end{array}$ & tc (h) & $\begin{array}{l}\text { Data - Hora } \\
\text { (Fim da cheia) }\end{array}$ & tc $(\mathrm{h})$ & $\begin{array}{l}\text { Data - Hora } \\
\text { (Fim da cheia) }\end{array}$ & tc (h) \\
\hline \multirow{20}{*}{ 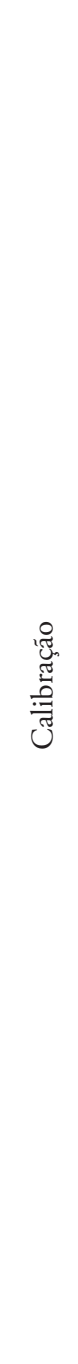 } & 1 & $26 / 10 / 2008-13: 49$ & 6,08 & $26 / 10 / 2008-02: 12$ & 5,97 & $10 / 08 / 2009-08: 30$ & 19,77 \\
\hline & 2 & $29 / 10 / 2008-14: 19$ & 2,08 & $26 / 10 / 2008-20: 12$ & 12,97 & 19/09/2009-00:10 & 18,73 \\
\hline & 3 & $06 / 11 / 2008-03: 49$ & 2,58 & $26 / 03 / 2011-12: 40$ & 13,23 & $11 / 11 / 2009-4: 20$ & 20,17 \\
\hline & 4 & 09/08/2009- 15:09 & 2,15 & $15 / 04 / 2011-4: 50$ & 13,90 & $23 / 11 / 2009-2: 50$ & 20,37 \\
\hline & 5 & $11 / 09 / 2009-21: 48$ & 2,78 & $14 / 07 / 2011-5: 50$ & 6,73 & $01 / 12 / 2009-2: 50$ & 20,37 \\
\hline & 6 & $18 / 09 / 2009-07: 48$ & 2,43 & $21 / 07 / 2011-10: 10$ & 11,45 & $23 / 09 / 2010-05: 40$ & 19,77 \\
\hline & 7 & $27 / 09 / 2009-12: 58$ & 1,47 & 03/01/2014-22:40 & 7,27 & $26 / 03 / 2011-17: 50$ & 16,68 \\
\hline & 8 & $22 / 09 / 2010-13: 06$ & 3,27 & $12 / 04 / 2014-15: 40$ & 12,70 & $15 / 04 / 2011-10: 40$ & 19,6 \\
\hline & 9 & 26/03/2011-02:47 & 3,35 & $31 / 05 / 2014-17: 10$ & 6,95 & $11 / 05 / 2011-13: 30$ & 21,85 \\
\hline & 10 & $14 / 04 / 2011-19: 02$ & 4,35 & $05 / 06 / 2014-20: 10$ & 9,95 & $14 / 07 / 2011-16: 00$ & 16,9 \\
\hline & 11 & $10 / 05 / 2011-22: 13$ & 1,95 & $14 / 6 / 2014-8: 30$ & 12,45 & $21 / 07 / 2011-15: 30$ & 17,03 \\
\hline & 12 & 14/07/2011-00:49 & 1,72 & $23 / 6 / 2014-17: 20$ & 7,45 & 09/08/2011-19:30 & 17,52 \\
\hline & 13 & $21 / 07 / 2011-01: 42$ & 3,23 & $25 / 6 / 2014-15: 10$ & 8,62 & $19 / 08 / 2011-12: 10$ & 18,72 \\
\hline & 14 & $12 / 04 / 2014-04: 56$ & 1,97 & $26 / 6 / 2014-15: 10$ & 13,45 & $12 / 04 / 2014-23: 50$ & 21,15 \\
\hline & 15 & $24 / 07 / 2014-00: 52$ & 4,17 & 7/9/2014 - 02:10 & 9,33 & $23 / 05 / 2014-02: 10$ & 17,97 \\
\hline & 16 & $06 / 09 / 2014-20: 10$ & 3,52 & $29 / 9 / 2014-08: 40$ & 7,42 & $14 / 06 / 2014-14: 20$ & 18,28 \\
\hline & 17 & $19 / 10 / 2014-12: 20$ & 5,35 & $13 / 10 / 2014-23: 50$ & 6,85 & $24 / 06 / 2014-2: 50$ & 18,95 \\
\hline & 18 & $06 / 11 / 2014-17: 40$ & 2,28 & 19/10/2014- $15: 40$ & 8,68 & $26 / 06 / 2014-01: 10$ & 18,62 \\
\hline & 19 & $10 / 01 / 2015-16: 56$ & 5,37 & 07/11/2014- 00:20 & 8,52 & $24 / 7 / 2014-16: 00$ & 19,47 \\
\hline & 20 & $20 / 01 / 2015-06: 23$ & 2,17 & $27 / 12 / 2014-14: 30$ & 6,73 & $7 / 9 / 2014-12: 30$ & 19,82 \\
\hline & & Máximo (h) & 5,37 & & 13,90 & & 21,85 \\
\hline & & Mínimo (h) & 1,47 & & 5,97 & & 16,68 \\
\hline & & Média (h) & 2,96 & & 9,53 & & 19,09 \\
\hline & & Mediana (h) & 2,58 & & 8,65 & & 19,21 \\
\hline & & esvio padrão (h) & 1,40 & & 2,04 & & 1,01 \\
\hline
\end{tabular}


Tabela 5 - Tempo de concentração obtido pelo método hidrológico para validar a equação "Projeto Potiribu"

\begin{tabular}{|c|c|c|c|c|c|c|c|}
\hline \multirow[b]{2}{*}{ Item } & \multirow[b]{2}{*}{ Evento } & \multicolumn{2}{|l|}{ Donato } & \multicolumn{2}{|l|}{ Turcato } & \multicolumn{2}{|l|}{ Taboão } \\
\hline & & $\begin{array}{c}\text { Data - Hora } \\
\text { (Fim da cheia) }\end{array}$ & $\begin{array}{l}\text { tc } \\
\text { (h) }\end{array}$ & $\begin{array}{c}\text { Data - Hora } \\
\text { (Fim da cheia) }\end{array}$ & tc (h) & $\begin{array}{c}\text { Data - Hora } \\
\text { (Fim da cheia) }\end{array}$ & tc (h) \\
\hline \multirow{10}{*}{ 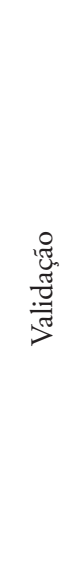 } & 21 & $05 / 01 / 2016-13: 50$ & 1,43 & $10 / 01 / 2016-16: 30$ & 11,33 & $10 / 01 / 2016-13: 50$ & 18,67 \\
\hline & 22 & $09 / 01 / 2016-20: 22$ & 1,37 & $14 / 02 / 2016-20: 10$ & 6,17 & $15 / 02 / 2016-02: 50$ & 12,17 \\
\hline & 23 & $14 / 02 / 2016-22: 32$ & 2,70 & 03/03/2016-02:00 & 5,00 & $26 / 03 / 2016-15: 30$ & 19,17 \\
\hline & 24 & $26 / 03 / 2016-00: 16$ & 3,60 & $26 / 03 / 2016-02: 50$ & 6,50 & $25 / 04 / 2016-21: 50$ & 16,5 \\
\hline & 25 & $25 / 04 / 2016-02: 35$ & 1,25 & $25 / 04 / 2016-16: 20$ & 11,00 & $19 / 10 / 2016-23: 50$ & 16,83 \\
\hline & 26 & $25 / 04 / 2016-04: 25$ & 1,25 & $31 / 12 / 2016-21: 10$ & 3,83 & 15/02/2017 - 09:40 & 12,67 \\
\hline & 27 & $25 / 04 / 2016-06: 55$ & 1,58 & $15 / 02 / 2017-02: 30$ & 6,17 & $26 / 04 / 2017-20: 20$ & 22,50 \\
\hline & 28 & $14 / 07 / 2016-10: 28$ & 1,80 & $26 / 04 / 2017-15: 00$ & 9,00 & $28 / 05 / 2017-11: 40$ & 22,00 \\
\hline & 29 & $14 / 07 / 2016-16: 18$ & 1,47 & $27 / 05 / 2017-23: 20$ & 9,67 & 01/06/2017 - 16:10 & 14,00 \\
\hline & 30 & $19 / 10 / 2016-08: 54$ & 1,73 & 09/06/2017 - 00:20 & 7,17 & 09/06/2017 - 06:00 & 26,1 \\
\hline \multicolumn{3}{|c|}{ Máximo (h) } & 3,60 & & 11,33 & & 26,10 \\
\hline \multicolumn{3}{|c|}{ Mínimo (h) } & 1,25 & & 3,83 & & 12,17 \\
\hline \multicolumn{3}{|c|}{ Média (h) } & 1,49 & & 7,58 & & 18,06 \\
\hline \multicolumn{3}{|c|}{ Mediana (h) } & 1,53 & & 6,84 & & 17,75 \\
\hline \multicolumn{3}{|c|}{ Desvio padrão (h) } & 0,75 & & 2,54 & & 4,54 \\
\hline
\end{tabular}

Figura 6 - Gráfico blox plot dos tempos de concentraçáo medidos do $1^{\circ}$ ao $20^{\circ}$ evento, utilizados para propor a equação, validados do $21^{\circ}$ ao $30^{\circ}$ evento, e calculados pelas equaçóes para as três bacias hidrográficas

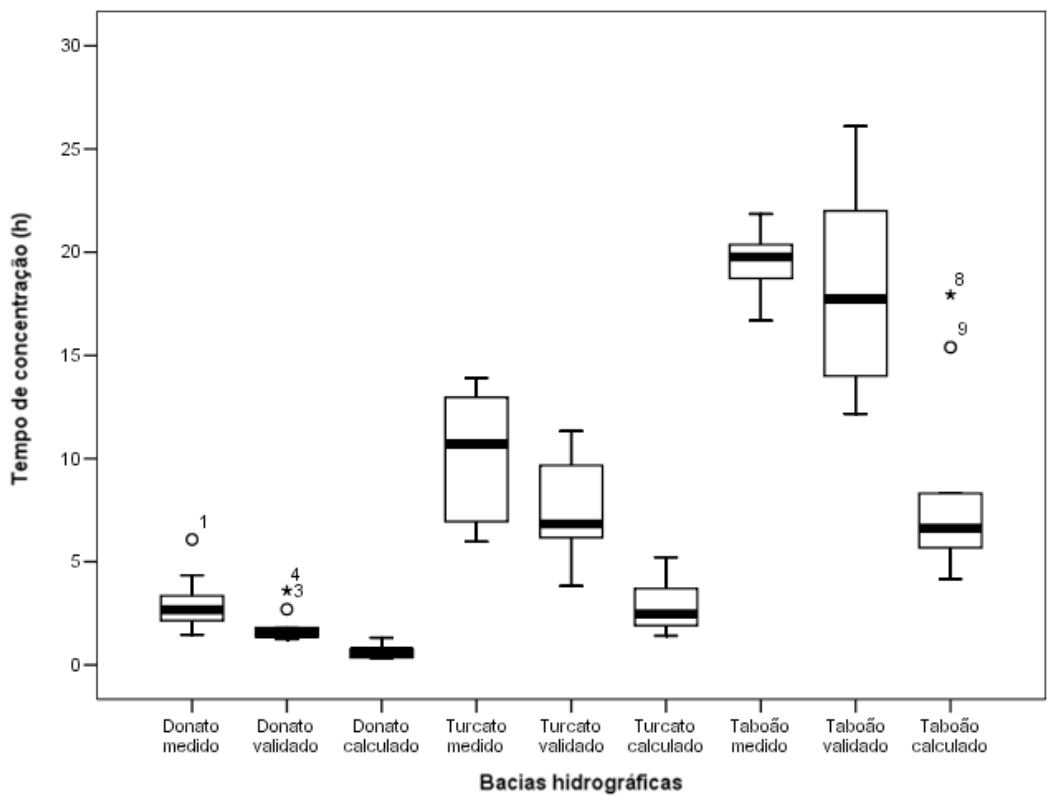


Tabela 6 - Tempo de concentração (tc) obtido pelas diferentes equações para cada bacia hidrográfica analisada

\begin{tabular}{|c|c|c|c|c|c|}
\hline Equação & Autor & Equação & $\begin{array}{c}\text { tc do } \\
\text { Donato (h) }\end{array}$ & $\begin{array}{c}\text { tc do } \\
\text { Turcato(h) }\end{array}$ & $\begin{array}{c}\text { tc do } \\
\text { Taboão (h) }\end{array}$ \\
\hline 1 & Kirpich & $\mathrm{tc}=0,0663 \mathrm{~L}^{0,77} \mathrm{~S}^{-0,385}$ & 0,33 & 1,63 & 5,68 \\
\hline 2 & George Ribeiro & $\mathrm{tc}=0,222(1,05-0,2 \mathrm{p})^{-1} \mathrm{LS}^{-0,04}$ & 0,35 & 1,91 & 6,77 \\
\hline 3 & Picking & $\mathrm{tc}=0,0883 \mathrm{~L}^{0,667} \mathrm{~S}^{-0,333}$ & 0,36 & 1,41 & 4,16 \\
\hline 4 & $\begin{array}{c}\text { Corps } \\
\text { Engineers }\end{array}$ & $\mathrm{tc}=0,191 \mathrm{~L}^{0,76} \mathrm{~S}^{-0,19}$ & 0,47 & 1,93 & 5,70 \\
\hline 5 & Ven te Chow & $\mathrm{tc}=0,160 \mathrm{~L}^{0,64} \mathrm{~S}^{-0,32}$ & 0,61 & 2,29 & 6,46 \\
\hline 6 & Dnos & $\mathrm{tc}=0,419 \mathrm{k}^{-1} \mathrm{~A}^{0,3} \mathrm{~L}^{0,2} \mathrm{~S}^{-0,4}$ & 0,66 & 2,98 & 7,89 \\
\hline 7 & Dooge & $\mathrm{tc}=0,365 \mathrm{~A}^{0,41} \mathrm{~S}^{-0,17}$ & 0,71 & 2,63 & 5,30 \\
\hline 8 & Pasini & $\mathrm{tc}=0,107 \mathrm{~A}^{0,333} \mathrm{~L}^{0,333} \mathrm{~S}^{-0,5}$ & 0,76 & 5,09 & 17,94 \\
\hline 9 & Ventura & $\mathrm{tc}=0,127 \mathrm{~A}^{0,5} \mathrm{~S}^{-0,5}$ & 0,84 & 5,22 & 15,39 \\
\hline 10 & Johnstone & $\mathrm{tc}=0,462 \mathrm{~L}^{0,5} \mathrm{~S}^{-0,25}$ & 1,32 & 3,70 & 8,31 \\
\hline 11 & SCS Lag & $\mathrm{tc}=0,057(1000 / \mathrm{CN}-9)^{0,7} \mathrm{~L}^{0,8} \mathrm{~S}^{-0,5}$ & 1,42 & 7,97 & 31,46 \\
\hline 12 & Giandotti & $\mathrm{tc}=0,0559\left(4,0 \mathrm{~A}^{0,5}+1,5 \mathrm{~L}\right) \mathrm{L}^{-0,5} \mathrm{~S}^{-0,5}$ & 1,89 & 5,57 & 11,19 \\
\hline \multirow[t]{6}{*}{13} & Simas Hawkins & $\mathrm{tc}=0,322 \mathrm{~A}^{0,594} \mathrm{~L}^{-0,594} \mathrm{~S}^{-0,150} \mathrm{~S}_{\mathrm{scs}}{ }^{0,313}$ & 2,20 & 5,06 & 6,24 \\
\hline & & Máximo (h) & 2,20 & 7,97 & 31,46 \\
\hline & & Mínimo (h) & 0,33 & 1,41 & 4,16 \\
\hline & & Média (h) & 0,92 & 3,65 & 10,19 \\
\hline & & Mediana (h) & 0,71 & 2,98 & 6,77 \\
\hline & & Desvio padrão $(\mathrm{h})$ & 0,61 & 1,99 & 7,59 \\
\hline 15 & Projeto Potiribu & $\mathrm{tc}=0,676 \mathrm{~L}^{0,079} \mathrm{~A}^{0,296} \mathrm{~S}^{-0,239}$ & 2,95 & 9,49 & 19,00 \\
\hline
\end{tabular}

influenciado para que os resultados se aproximassem, a exceção da equaçáo de George Ribeiro que apresenta uma variável a mais que está relacionada a fração de área com mata. Ainda, é possível perceber que as equaçóes 6 , $8,9,10,11$ e 12 tendem a elevar consideravelmente o tempo de concentração à medida que a área da bacia e o comprimento do rio principal aumentam.

Verificou-se que, as equaçóes da Tabela 6 subestimaram o tc em relação ao calculado pelo método hidrológico, tanto para os 20 primeiros eventos (Tabela 4), como para os 10 últimos (Tabela 5). Com exceção da equação SCSLag que superestimou o tc para a bacia do Taboão (64,82\% superior).

Mota (2012) utilizando diversas equaçóes empíricas observou que os valores de tc foram subestimados e apresentaram erros superiores a $90 \%$ em relaçáo a equação proposta pela autora usando dados medidos para uma bacia rural no norte de Santa Catarina. Resultado semelhante foi verificado no presente trabalho, por exemplo, com a equação de Kirpich, que subestimou em 88,81\%, 
$82,83 \%$ e $70,11 \%$ o tc para as bacias do Donato, Turcato e Taboão, respectivamente, em comparação com a Equação 15. Kobiyama et al. (2006), utilizando 5 eventos de cheia para o cálculo do tc de uma bacia urbana através do método hidrológico, também verificaram que as equaçóes empíricas subestimam o tc.

As equaçóes que mais se aproximaram do método hidrológico na obtenção do tc foram: a equação de Simas-Hawkins (erro de 25,61\%), para os 20 primeiros eventos e a equação de SCS LAg (erro de 4,38\%), para os 10 últimos eventos, para a bacia do Donato; já para a bacia do Turcato a equaçáo do SCS Lag, erro de 16,38\%, para os 20 eventos da calibração e erro de 5,09\% para os 10 eventos da validaçáo; e equação de Pasini, erro de 6,01\%, para os 20 eventos da calibraçáo e erro de $0,67 \%$ para os 10 eventos da validaçáo para a bacia do rio Taboão. Esses resultados estão coerentes considerando que, a equação de Simas-Hawkins foi desenvolvida para bacias hidrográficas menores que $15 \mathrm{~km}^{2}$. Já a equação do SCS Lag, desenvolvida para bacias até $8 \mathrm{~km}^{2}$, teve melhor resultado para a bacia do Turcato $\left(17,25 \mathrm{~km}^{2}\right)$, o que pode estar associado a consideraçáo do parâmetro $\mathrm{CN}$, implicando assim, em efeitos sobre o escoamento superficial.

$\mathrm{Na}$ Figura 6 é apresentado um gráfico blox-plot resumindo os resultados dos tc estimados para os 20 primeiros e 10 últimos eventos pelo método hidrológico e estimados e também calculados pelas equaçóes empíricas para as três bacias. Verifica-se que à medida que as bacias hidrográficas aumentam de tamanho, a amplitude entre os tcs calculados aumenta, ou seja, os valores passam a divergir de forma mais acentuada em relação a mediana.

\section{CONCLUSÓES}

Com o objetivo de avaliar o tc para bacias rurais de diferentes escalas foi proposta uma equação empírica baseada no tc médio obtido pelo método hidrológico.
Os tcs obtidos pelo método hidrológico apresentaram grande variabilidade, sendo de $27,37 \%$, $42,95 \%$ e $76,39 \%$, para as bacias do Donato, Turcato e Taboão, respetivamente, mostrando que, quanto maior a área da bacia, maior a variação do tc.

Para comparar os resultados obtidos pelo método hidrológico foram utilizadas 13 equaçóes empíricas desenvolvidas para bacias rurais. O tc calculado por essas equaçóes foi subestimado para todas as bacias, com exceção da equação do SCS Lag que superestimou o tc da bacia do Taboão. Esta última pode ter sido influenciada por considerar o parâmetro CN do método SCS. Para as bacias hidrográficas analisadas no presente trabalho, os melhores resultados foram obtidos com as equaçóes propostas por Simas-Hamkins, SCS Lag e Pasini.

Os resultados deste estudo demonstram a importância de considerar as características físico-hídricas do local para as quais as equaçóes são aplicadas, por isso, deve-se ter cautela em utilizá-las.

Sugere-se que a equação proposta neste trabalho, seja utilizada em bacias hidrográficas rurais, com características físicas e hídricas semelhantes às deste estudo para estimar o tc. No entanto, recomenda-se que se faça uma avaliaçáo criteriosa das características da bacia e comparar com outras existentes.

\section{AGRADECIMENTOS}

Ao CNPq pelas bolsas de Doutorado do primeiro autor e de produtividade em pesquisa do segundo autor.

A FINEP pelo financiamento da pesquisa em diversos projetos desde o ano de 2004 que permitiu o monitoramento das áreas em estudo.

\section{Referências}

BORDAS, M.P.; BORGES, A.L. Escolha de bacias representativas e experimentais para estudo da erosão no planalto basáltico sul americano. In: Congresso brasileiro e encontro nacional de pesquisa sobre conservação do solo, 8, Londrina, 1990. Anais. Londrina, Sociedade Brasileira e Ciência do Solo, 1990. p.15-1

CARVALHO, A.P.; ABRÃO, P.U.R.; FASOLO, P.J.; POTTER, R.J. Levantamento semidetalhado dos solos da bacia do arroio Taboão. (Pejuçara/ ljuí RS). Publicação interna. Porto Alegre: IPH/UFRGS, 1990. 41p. + Mapa 1:25.000. 
CASTRO, N. M.; CHEVALLIER, P.; GOLDENFUM, J. Projeto Potiribu -Atualização: 1989-1998. Dados básicos de fluviometria e pluviometria. Recursos Hídricos, Porto Alegre, v. 35, p. 01-61, 2000.

CASTRO, N.M.R., AUZET, A.V., CHEVALLIER P., LEPRUN, J-C. Land use change effects on runof and erosion from plot to catchment scale on the basaltic plateau of Southern Brazil. Hydrol. Process. V. 13, p. 1621-1628. 1999.

CASTRO, N. M. R. et al. Relatório Final das atividades desenvolvidas no projeto MATASUL de março 2007 a maio de 2010. 2010. 284 páginas + anexos (Relatório de pesquisa).

CGIAR-CSI, Consorctium spacial for information, 2017 . Disponivel em: <ttp://srtm.csi.cgiar.org///>.Acesso em: 13 jun. 2017.

CHEVALLIER P.; DHEIN R. A. Les précipitations exceptionnelles des 26 et 27 mai 1992 dans la région d'ljuí (Rio Grande do Sul, Brésil). Sécheresse 4, pp. 159-164. 1993.

CHOW, V. T. Hydrologic determination of waterway areas for the design of drainage structures in small drainage basins. University of Illinois. Engineering Experiment station Bulletin, $n^{\circ}$ 462. 1962.

COLLISCHONN, W.; DORNELLES, F. Hidrologia para engenharia e ciências ambientais. Associação Brasileira de Recursos Hídricos. Porto Alegre-RS. 2013.

DAEE. Hidrologia Urbana: Primeiro relatório parcial. Departamento de Águas e Energia Elétrica-SP. Escola Politécnica da USP. 1978.

GERGOV, G. Determination of the time of travel along the river network. Journal of Hydrology. V. 14, pg. 293-306. 1971.

EMBRAPA - EMPRESABRASILEIRADE PESQUISAAGROPECUÁRIA- EMBRAPA. Centro Nacional de Pesquisa de Solos. Sistema brasileira de classificação de solos. 2. ed. Rio de Janeiro: - SPI, 2006. 306p

IPAGRO - INSTITUTO DE PESQUISAS AGRONÔMICAS. Atlas agroclimático do Estado do Rio Grande do Sul. Secretaria de Agricultura e Abastecimento. V.1. 1989

JACOMINE, P. K. T. A nova classificação brasileira de solos. Anais da Academia Pernambucana de Ciência Agronômica. Recife. 2009.

KIRPICH, Z. P. Time of concentration of small agricultural watersheds. J. of Civ. Eng., v. 10, nº, p. 362. 1940.

KOBIYAMA, M; GRISON, F.; LINO, J. F. L.; SILVA, R. V. Estimativa morfométrica e hidrológica do tempo de concentração na bacia do campus da UFSC, Florianópolis-SC. ABRH. I Simpósio de Recursos Hídricos Sul-Sudeste. 2006

MCCUEN, R. H. Hydrologic analysis and design. Second edition. Prentice Hall. 1998.

MCCUEN, R. H.; WONG, S. L.RAWLS, W. J. Estimating urban time of concentration. Hydraul. Eng., V110, nº 7, p. 887-904. 1984.

MOPU TECNOLOGIA CARRETERAS. Cálculo hidrometereológico de caudales máximos em pequenas cuencas naturales. Textos de la Direccion General de Carreteras, n¹2, 124 pg. Espanha. 1987.

MOTA, A. A. Tempo de concentração em pequena bacia experimental, 2012, 131 p, Dissertação (Mestrado em Engenharia Ambiental). Universidade Federal de Santa Catarina. Florianópolis, 2012. Available at https://repositorio.ufsc.br//mmlui/bitstream/handle/123456789/100709/311941. pdf?sequence=1\&isAllowed=y 
MOTA, A. A. Tempo de concentração em pequena bacia experimental. Dissertação de Mestrado. UFSC. Florianópolis. 2012.

NIMER, E. Climatologia do Brasil. Fundação IBGE. $2^{\circ}$ ed. Rio de Janeiro. 1989.

PORTO, R. L.L. Escoamento Superficial direto. In: "TUCCl et al. Drenagem Urbana. Coleção ABRH de Recursos Hídricos, vol. 5. ABRH". Porto Alegre. 1995.

RAMSER, C. E. Run-off from small agricultural areas. Journal of Agricutural Research. Vol 34. № 9. Washington, D. C. 1927.

SILVEIRA, A. L. L. Desempenho de fórmulas de tempo de concentração em bacias urbanas e rurais. Revista Brasileira de Recursos Hídricos (RBRH). Vol. 10, n¹. Porto Alegre. 2005.

SIMAS, M. J.; HAWKINS, R. H. Lag time characteristics for small watersheds. In http://www.nrcs.usda.gov/Internet/FSE_DOCUMENTS/ stelprdb1044199.pdf. 1996.

TUCCI, C. E. M.; SILVEIRA, A. L. L; BENETTI, A.; LANNA, A. E. L.; BIDONE, F.; SEMMELMAN, F.; LOUZADA, J. A. BERTONI, J. C.; FILHO, K. Z.; BELTRAME, L. F. S.; BORDAS, M. P.; PESSOA, M. L.; CAICEDO, N. L.; CHEVALLIER, P.; PORTO, R. L. CLARKE, R.T. Hidrologia: Ciência e Aplicação. $4^{\circ}$ Edição, Editora UFRGS. ABRH. 2009.

USDA. Linear theory of hydrological systems. Technical Bulletin. United States Departement of Agriculture. № 1468, Washinghton. 1973.

WATT, W. E.; CHOW, K. C. A. A general expression for basin lag time. Can. J. Civil Eng. 12, 294-300.1985.

\section{Felipe M. P. Mamédio Universidade Federal do Rio Grande do Sul,} Porto Alegre, RS, Brasil. email: fmp_mamedio@hotmail.com Contribuição do autor:

Escolha dos eventos, cálculo dos tempos de concentração, elaboração das figuras e tabelas, escrita geral.

Nilza M.R. Castro Universidade Federal do Rio Grande do Sul, Porto Alegre, RS, Brasil. email: nilza@iph.ufrgs.br Contribuição do autor:

Proposta de análise dos dados, sugestáo dos eventos escolhidos, escrita geral.

Cláudia W. Corseiul Universidade Federal de Santa Catarina, Araranguá, SC, Brasil email: cwcorseuil@hotmail.com Contribuição do autor:

Revisão geral do artigo, análise dos resultados, escrita geral. 